\title{
R\&D ERL: 5 Cell 704 MHz SRF Cavity
}

\author{
A. Burrill
}

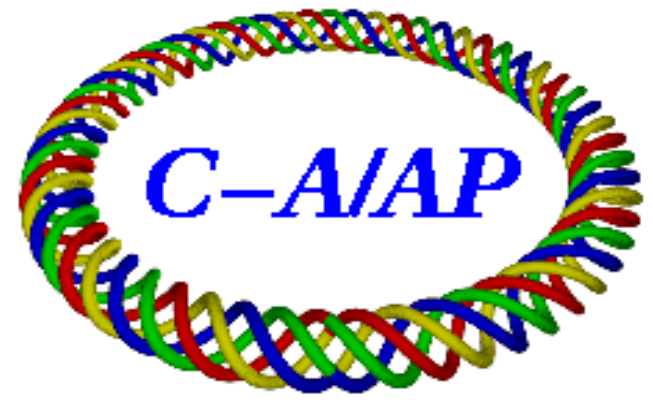

\section{Collider-Accelerator Department Brookhaven National Laboratory Upton, NY 11973}

Notice: This document has been authorized by employees of Brookhaven Science Associates, LLC under Contract No. DE-AC02-98CH10886 with the U.S. Department of Energy. The United States Government retains a nonexclusive, paid-up, irrevocable, world-wide license to publish or reproduce the published form of this document, or allow others to do so, for United States Government purposes. 


\title{
R\&D ERL - 5 Cell 704 MHz SRF Cavity
}

\author{
Andrew Burrill
}

\begin{abstract}
One of the key components for the superconducting RF Energy Recovery Linac, (ERL) under development in the Collider Accelerator Department at Brookhaven National Laboratory, is the Linac cavity and cryomodule. The cavity is a 5 cell accelerating cavity designed to operate at 703.75 MHz, and to accelerate $2 \mathrm{MeV}$ electrons from the photoinjector up to $15-20 \mathrm{MeV}$, allow them to make a single pass around the ERL loop and then decelerate them back down to $2 \mathrm{MeV}$ prior to sending them to the beam dump. This cavity was designed by Rama Calaga and Ilan Ben-Zvi at BNL and fabricated by Advanced Energy Systems in Medford, NY. The cavity was then delivered to Thomas Jefferson Laboratory in VA for chemical processing, testing and assembly of the hermetic string assembly suitable for shipment back to BNL. Once at BNL it was built into a complete cryomodule, installed in the ERL test facility and commissioned. This paper will review the key components of the cavity and cryomodule and discuss the present status of the cryomodule commissioning.
\end{abstract}

\section{INTRODUCTION}

The BNL 5 cell accelerating cavity has been designed [1] for use in our high average current Energy Recovery Linac, a proof of principle machine to demonstrate key components necessary for the future upgrades to RHIC [2] as well as applications for future ampere class high current, high brightness ERL programs. The cavity has been tested at greater than $20 \mathrm{MV} / \mathrm{m}$ with a $\mathrm{Q}_{0}$ of $1 \mathrm{e}^{10}$, meeting the design specifications for use at full energy in the ERL. This paper will review the cavity design and specifications as well as the RF measurements that have been made both in the VTA at Jefferson Lab as well as during the commissioning in the ERL test cave at BNL. Finally the future plan for cavity testing and measurements prior to its use in ERL operations will be reviewed.

The general physics parameters for the cavity can be found in table 1 , and the reader is referred to Rama Calaga's Thesis [3] for a much more detailed review of the cavity geometry and design. There are several different parameters that make this cavity design very unique. The first is the $17 \mathrm{~cm}$ diameter cavity iris and $24 \mathrm{~cm}$ diameter beampipe. The geometry, along with the cavity design, results in a cavity with no trapped higher order modes, and a BBU threshold is $>2$ amperes. Another feature of the geometry of this particular cavity is the fact that the lowest mechanical resonance is at $\sim 200 \mathrm{~Hz}$, thus making it much less susceptible to microphonics.

Table 1. The main SRF cavity parameters of the BNL 5 cell Linac Cavity. 


\section{BNL Cavity}

Main Parameters:

\begin{tabular}{|l|l|}
\hline \hline Frequency & $703.75[\mathrm{MHz}]$ \\
RHIC Harmonic & 25 \\
\hline Number of cells & 5 \\
Active cavity length & $1.52[\mathrm{~m}]$ \\
Iris Diameter & $24[\mathrm{~cm}]$ \\
Beam Pipe Diameter & 225 \\
\hline$G(\Omega)$ & $403.5[\Omega]$ \\
$R / Q$ & $4.5 \times 10^{10}$ \\
$Q$ BCS @ 2K & $3 \times 10^{7}$ \\
$Q_{e x t}$ & 1.97 \\
\hline$E_{p} / E_{a}$ & $5.78[\mathrm{mT} / \mathrm{MV} / \mathrm{m}]$ \\
\hline$H_{p} / E_{a}$ & $3 \%$ \\
\hline Cell to cell coupling & 833 \\
Sensitivity Factor $\left(\frac{N^{2}}{\beta}\right)$ & $96.5 \%$ \\
\hline Field Flatness & $1.2\left[\mathrm{~Hz} /(\mathrm{MV} / \mathrm{m})^{2}\right]$ \\
\hline Lorentz Detuning Coeff & $96[\mathrm{~Hz}]$ \\
\hline Lowest Mech. Resonance & $1.1[\mathrm{~V} / \mathrm{pC}]$ \\
\hline$k_{\|}\left(\sigma_{z}-1 \mathrm{~cm}\right)$ & $3.1[\mathrm{~V} / \mathrm{pC} / \mathrm{m}]$ \\
$k_{\perp}\left(\sigma_{z}-1 \mathrm{~cm}\right)$ & $0.5-2.3[\mathrm{~kW}]$ \\
\hline HOM Power (10-20 nC) & \\
\hline \hline
\end{tabular}

\section{CAVITY PROCESSING AND TESTING}

Following the cavity fabrication and initial bench-top measurements the cavity was shipped to Jefferson Lab for processing and testing. The initial cavity processing plan was as follows:

1. CMM measurements of the cavity dimensions.

2. RF beadpull to determine frequencies of cavities modes as well as field flatness in the 5 cells, followed by calibration of the input and field probes.

3. 200 um buffer chemical polishing (1:1:2 conc. hydrofluoric, conc. nitric, phosphoric acid)

4. $600^{\circ} \mathrm{C}$ bake for 10 hours to remove hydrogen following heavy chemistry

5. Degreasing of the cavity for 1 hour

6. Light BCP, typically 20 um

7. High pressure water rinse for 6 hours on the BNL HPR (2 - 40 degree nozzles, 2.4 GPM at $1500 \mathrm{psi})$

8. Initial assembly of one half of the cavity flanges

9. Second HPR for 6 hours 
10. Final assembly and leak check of cavity

11. Testing in VTA to determine RF performance

12. Repeat steps 5-10 until desired performance is achieved.

13. If the desired performance is not reached via these steps implement new plan.

The cavity processing and testing had numerous hurdles to overcome as this was a unique cavity to test, but in the end the cavity reached the desired gradient and Q. Figure 1 shows the Q vs Eacc curve for the cavity at various stages in the processing cycle. The measured cavity performance after low temperature baking as well as attachment of the helium vessel can be seen in the graph.

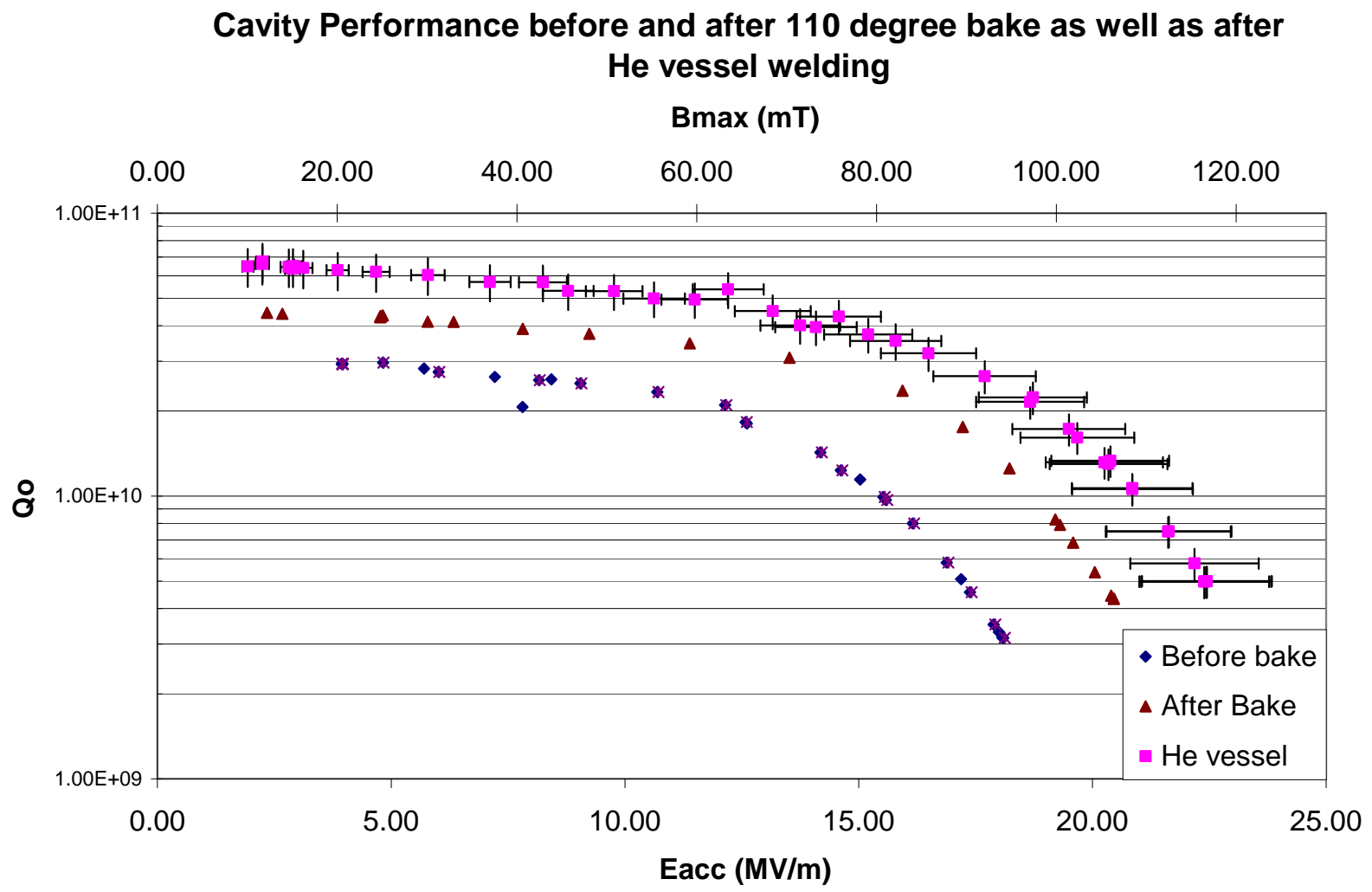

Figure 1. The plot of Qo vs Eacc for three tests on the 5 cell cavity. The blue circles are before the 110 degree bake, the red triangles are after the 110 degree bake and the pink squares are with the He vessel attached.

\section{STRING ASSEMBLY}

Following the VTA cavity testing the cavity string assembly began. This process was carried out in the class 100 cleanroom at Jefferson Lab and included the installation of all of the beamline components that are located between the isolation valves on either end of the string. Figure 2 shows the completed string assembly which is effectively symmetric about the 5 cell cavity. The 
key components shown moving away from the cavity are 1) the $5 \mathrm{~K}$ liquid helium cooled thermal transitions with dual bellows to compensate for thermal contraction and expansion. 2) The beam position monitors, in this case 3 simple antennas per side that will be used to determine the location of the beam as it passes through the cavity. 3) The water cooled ferrite higher order mode (HOM) dampers, utilizing the nickel-zinc ferrite C-48 ferrite tiles. [4] 4) A beamline step reduction section with $20 \mathrm{l} / \mathrm{s}$ ion pumps and burst disks and finally the all metal seal valves.

Upon completion of the string assembly the cavity was shipped to BNL for integration into the cryomodule and installation into the cave.

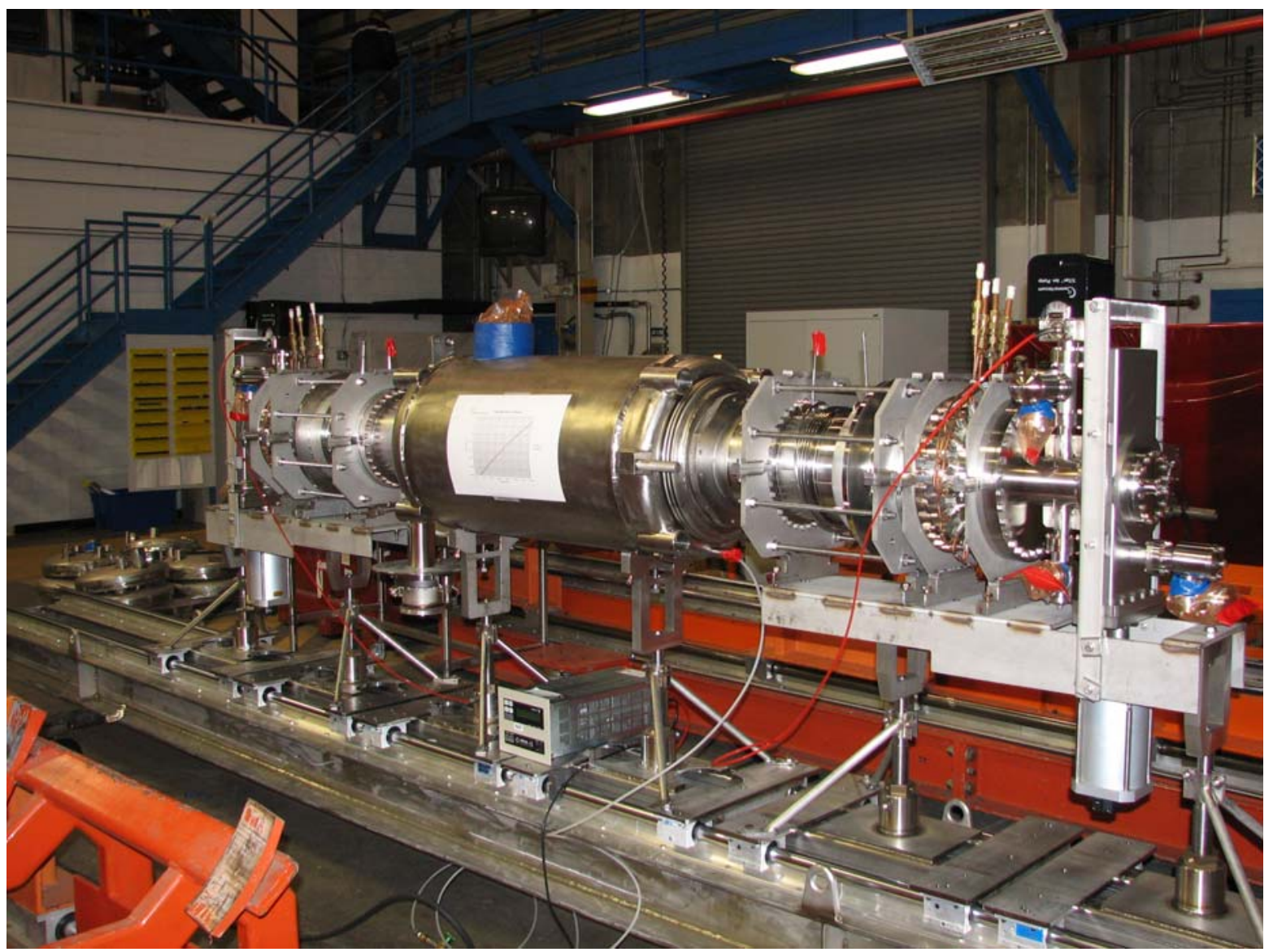

Figure 2. The ERL accelerating cavity hermetic string assembly shown prior to shipment to BNL for installation into the cryomodule.

\section{CRYOMODULE INTEGRATION}

Once back at BNL the hermetic string assembly was built into a cryomodule consisting of two layers of magnetic shielding, multi-layer super insulation, a liquid nitrogen shield, installation of the cavity tuner mechanism, and finally the vacuum vessel. The tuner mechanism is composed of a coarse mechanical stepper motor which was designed to provide $400 \mathrm{kHz}$ of tuning range, as well as a piezo-electric drive for fine adjustment which provides $9 \mathrm{kHz}$ of tuning range. Due to 
safety concerns the coarse tuner adjustment was limited to $100 \mathrm{kHz}$ of tuning range, which is still more than adequate for our prototype ERL operation.

Following the cryomodule construction the unit was moved to the ERL facility and positioned under the liquid helium ballast tank, designed to provide operational liquid helium at 2 Kelvin. Figure 3 shows the cavity installed in the blockhouse and attached to the related helium and vacuum vent lines. Due to the fact that a liquid helium refrigerator was not part of the original plan the cryomodule was designed with the aforementioned ballast tank. For operations the system is filled with LHe and then a liquid ring pump is used to reduce the pressure over the helium bath and provide stable operation at $2 \mathrm{~K}$.

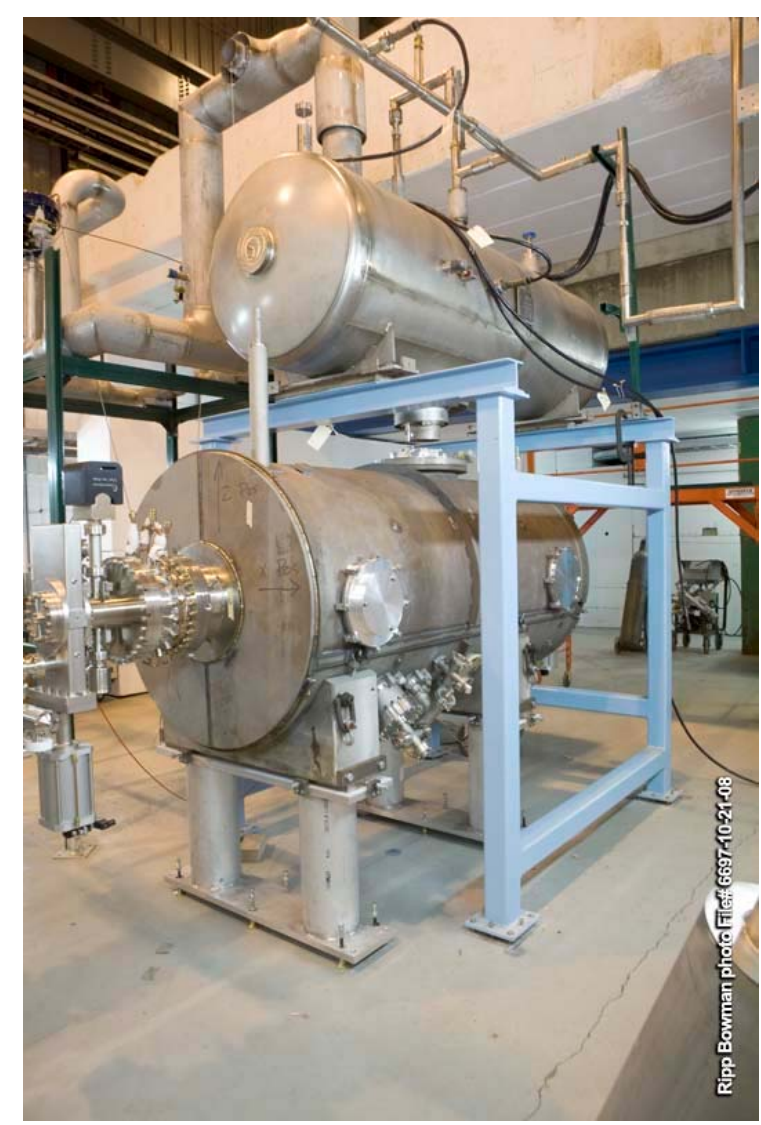

Figure 3. The cryomodule and liquid helium ballast tank installed in the ERL blockhouse.

\section{FUNDAMENTAL POWER COUPLER RE-CONDITIONING}

Once the cryomodule installation was completed the commissioning tasks began. One of the first items addressed was the re-conditioning of the FPC. The FPC was originally conditioned 2 years prior to it's insertion into the hermetic string on a resonant waveguide box with the help of ORNL. Due to the amount of time between the original conditioning and the ERL commissioning it was decided that it may prudent to re-condition the FPC prior to operation. This task was carried out at room temperature to conserve liquid helium in the event the 
conditioning process took more than an hour or two. The FPC is designed to operate at $10 \mathrm{~kW}$ power c.w. during routine cavity operation, while the RF transmitter can produce $50 \mathrm{~kW}$ power CW. As the RF power was available for use, the full $50 \mathrm{~kW} \mathrm{RF}$ power was used for conditioning. The cavity was at $150 \mathrm{~K}$ when the conditioning was carried out, and there were no arcing events or vacuum trips during the conditioning operation. The power was raised to $47 \mathrm{~kW}$ without incident and the processes declared a success. The vacuum level in the cavity was $1 \mathrm{e}^{-9}$ Torr as measured on two cold cathode gauges on the flange of the FPC as well as measured by the beamline cold cathode gauge in the warm section of the cavity beampipe. The vacuum pressure only rose slightly due to thermal heating of the FPC antenna to $1.8 \mathrm{e}^{-9}$ Torr at $47 \mathrm{~kW}$. The temperature of the ceramic window was monitored by an RTD mounted to the flange on which the ceramic is brazed. The temperature of the flange rose $20 \mathrm{~K}$ during the conditioning operation and peaked at $308 \mathrm{~K}$. The FPC inner conductor is water cooled and the vacuum side outer conductor is cooled by LHe, or in this case $\mathrm{LN}_{2}$, while the ceramic window itself is maintained at $15^{\circ} \mathrm{C}$ to avoid ice-ball formation or excess thermal stress on the window.

\section{CRYOMODULE TESTING}

Following the FPC conditioning and testing of other associated systems a preliminary cryogenic test was carried out to measure the operational parameters for the cryostat. The goal of the test was to study the thermal characteristics of the system as well as to measure the static losses in the system and the associated sub-systems.

The initial cooldown was very successful with all subsystems working as designed. The static heat load at $4 \mathrm{~K}$ was measured to be $\sim 25$ watts based on the helium return mass flow meter, within about $5 \%$ of the calculated heat load of the system. After this measurement was made the cavity was cool down to $1.8 \mathrm{~K}$ to test the operation of the liquid ring pump and ensure all of the associated systems operated correctly. The cool-down to $1.8 \mathrm{~K}$ was monitored closely to optimize the liquid helium loss and resulted in $\sim 30 \%$ reduction in liquid level. The normal operation of the ERL requires $2.1 \mathrm{~K}$ operation, however the system was tested to $1.8 \mathrm{~K}$ as this pump will also be used for vertical cavity testing in our Vertical Test Facility.

Following the cryomodule shakedown RF testing of the cavity began. To date there have been three tests of the cryomodule and a great deal of data has been collected to better understand our cryomodule performance, microphonics, and field emission in the cavity. The cavity was operated at both $4 \mathrm{~K}$ and $2 \mathrm{~K}$ and a gradient of $\sim 20 \mathrm{MV} / \mathrm{m}$ was measured at $2 \mathrm{~K}$. This value is inline with both the design specification for the system and agrees well with the data collected during the VTA testing of the cavity. The operation of the LLRF system, the phase lock loop, and the tuner drive system were all tested and worked as designed. Additionally microphonics measurements were made on multiple occasions in a very systematic approach in order to understand the root of the various vibrations and to understand how they may be dampened.

The cavity testing was limited to three single day tests due to the amount of helium available based on our ballast tank design. Future tests will not be limited in duration as there have been several solutions implemented that will allow for continuous running for several days, or weeks 
once the refrigerator is on-line. The first RF test of the cavity found that the cavity has a bit of field emission that needs to be processed before the cavity can be run c.w. During this first test it was possible to measure the maximum gradient in the cavity as well as study the field emission onset. From this data it was decided to implement a helium processing set-up for the following test. The second test was plagued by an increased heat load due to an ice-ball formation in one of the heat intercepts, thus making testing nearly impossible, but a wealth of microphonics measurements were made that are currently under evaluation. The last test allowed us to begin helium processing in earnest, and resulted in modest reduction of field emission. The test was cut short by a lack of liquid helium and due to operational issues with the gaseous helium introduction. The next test, planned for early 2010 will addressed these issues through the following solutions. First a continuous liquid helium supply will be available thanks to a modification of the RHIC cryogenic plant. Second, the helium gas introduction will be done using a remote controlled leak valve such that it will not be necessary to enter the block house to introduce or remove helium gas from the cavity. This will also allow for the introduction of helium while the RF power is applied. Finally a self excited loop is being built to facilitate tracking the frequency changes that result from the introduction of helium for processing, as well as from the changes in resonant frequency that occur during the helium breakdown process.

\section{CONCLUSIONS}

The 5 cell cavity has been successfully fabricated and tested in the VTA to demonstrate 20 $\mathrm{MV} / \mathrm{m}$ gradient at a $\mathrm{Q}_{0}$ of $1 \mathrm{e} 10$. The cryomodule has been successfully built and preliminary testing carried out. Data analysis is ongoing to understand the microphonics spectrum found, and helium processing is being implemented to address the field emission in the cavity. Overall the cavity should be demonstrated at the desired gradient and with reasonable to no field emission in the next 3 months.

\section{REFERENCES}

[1] R. Calaga, I. Ben-Zvi, Y. Zhao, "High Current Superconducting Cavities at RHIC," EPAC’04, Lucerne, July $\quad 2004, \quad$ p. http://accelconf.web.cern.ch/AccelConf/e04/PAPERS/TUPKF078.PDF

[2] V.N. Litvinenko et al., "High Current Energy Recovery Linac at BNL,” Proceedings of the 2004 FEL conference, $\quad$ p http://accelconf.web.cern.ch/AccelConf/f04/papers/TUPOS64/TUPOS64.PDF

[3] R. Calaga, “Linac Beam Dynamics \& Ampere Class Superconducting RF Cavities at RHIC,” Stony Brook University 2006, http://www.agsrhichome.bnl.gov/People/rcalaga/thesis.html

[4] H. Hahn, A. Burrill, R. Calaga, D. Kayran and Y. Zhao, “ R Squared impedance of ERL ferrite HOM absorber,” Physica C: Superconductivity, 441 (2006) 239-42. 